\title{
Infection control practices: Awareness and Knowledge of Undergraduates in Tertiary Care Hospital
}

\author{
Manali Hitenbhai Shah and Latika Nitin Purohit* \\ Department of Microbiology, Government Medical College, Surat, Gujarat, India.
}

\begin{abstract}
Background: Hospital acquired infection an infection occurring in a patient in a hospital or other health care facility in whom the infection was not present or incubating at the time of admission. Every person associated with health care work should have proper training, knowledge and practice for the same. Undergraduates do not have proper knowledge towards the health care management. As they are in the learning phase, need to train enough.

Methods: It was an observational analytical study. 2nd year MBBS students were included in the study. A semi-structured preformed questionnaire of total 21 questions having multiple choice questions with the use of Google doc application. Data were analyzed by using Microsoft Excel program.

Result: Total 143 2nd year MBBS students responded. Knowledge regarding needle stick injuries was 40-60\% while about MDR and XDR TB was up to $70-80 \%$. Around $60 \%$ knew the correct dosage schedule of Hepatitis B vaccine whereas $70 \%$ emphasized the importance of hand hygiene in hospital acquired infections.

Conclusion: The study shows lack of knowledge and awareness amongst medical students about hospital acquired infections. There is to educate them enough by means of various curriculum activities. More such studies should be done in future to assess their KAP score and guide them well.
\end{abstract}

Keywords: Hospital Acquired Infection, Undergraduates, Awareness and Knowledge.

\section{Introduction}

Hospital acquired infection an infection occurring in a patient in a hospital or other health care facility in whom the infection was not present or incubating at the time of admission. This includes infections acquired in the hospital but appearing after discharge, and also occupational infections among staff of the facility ${ }^{[1]}$. It is a global problem ${ }^{[2]}$ which is encountered during the stay in the hospital ${ }^{[3]}$. All medical and paramedical staff including doctors, medical students, nursing staff, nursing students, ward persons and any other person which is directly or indirectly associated with health care work which can be patient care or waste management. Patient's care and waste management are the most important aspects which ultimately deals with the Hospital acquired infections ${ }^{[3]}$. Every person associated with this work should have proper training, knowledge and practice for the same. Amongst the members associated with these activities, medical students which are attending the wards in their undergraduate posting are also a most important part of health care. Undergraduates do not have proper knowledge towards the health care management and even hospital acquired infections ${ }^{[4]}$. As they are in the learning phase, they need to train enough ${ }^{[5]}$ for the patient care, biomedical waste management, personal protective equipment, hand hygiene, infectious diseases associated with health care management or faulty practices. As they will be the future interns or postgraduates, they need to understand the importance of hospital acquired infections, how to take personal protective measures, how and when to get post exposure prophylaxis, what are the different routes of infections, which are the diseases spread by contact with blood. To implement this, step by step procedure is needed in the form of assessment of knowledge, analysis, monitoring their practices, training of them at regular intervals and more. The study was planned to assess the knowledge of $2^{\text {nd }}$ year MBBS students (Undergraduates) regarding infection control practices, which have just started going to wards and having clinical site exposure.

\section{Materials and Methods}

It was an observational analytical study. $2^{\text {nd }}$ year MBBS students of Government Medical College, Surat and SMIMER (Surat Municipal Institute of Medical Education and Research) were included into the study. A semistructured preformed questionnaire of total 21 questions having multiple choice questions was prepared with the use of Google doc application. Questions were mainly based on knowledge of commonly encountered practices like needle stick injury, personal protective equipments, 
post exposure prophylaxis, blood borne infections, air borne infections, route of transmission of different diseases etc ${ }^{[6,7,8]}$. The students were asked to fill the appropriate answers using Google doc application and give comments if they want. Total 143 students responded from different Batches of Undergraduates. After decoding their identity by giving them dummy numbers, their data were analyzed by using Microsoft Excel program.

\section{Questionnaire asked to the students:}

1. Do you know that Needle prick injuries are to be noted?
(a) Yes
(b) No

2. Do you know where and whom to report needle prick injuries?
(a) Yes, I do
(b) No, I do not

3. Do you know from where you can get post exposure prophylaxis for HIV positive splash or Needle prick?
(a) Yes
(b) No

4. Universal precautions during any procedure should be taken against:
(a) Any clinical procedure
(b) Patients with HIV and Hepatitis B disease
(c) Patients with HCV disease
(d) Patients with any transmissible disease

5. Needles have to be recapped immediately after use:
(a) Agree
(b) Do not agree

6. Transmission of tuberculosis is air-borne?
(a) True
(b) False

7. What is MDR TB?
(a) Resistance to Rifampin and/or Isoniazide
(b) Resistance to Rifampin, Isoniazide, Ethambutol
(c) Resistance to all primary line of drugs
(d) Resistance to all primary and secondary line of drugs

8. What is XDR TB?
(a) Extensive drug resistance
(b) Excessive drug resistance
(c) Exclusive drug resistance
(d) Extrapulmonary drug resistance

9. Swineflu is transmitted by?
(a) Close contact to the diseased person
(b) Needle prick from diseased person
(c) Through Gastrointestinal tract
(d) None of the above

10. Swineflu virus is:
(a) H1N1
(b) $\mathrm{H} 1 \mathrm{~N} 5$
(c) $\mathrm{H} 1 \mathrm{~N} 3$
(d) $\mathrm{H} 2 \mathrm{~N} 5$

11. What precautions to be taken before going to any ward?
(a) Take heavy breakfast
(b) Wear appropriate personal protective equipments
(c) Cover all broken skins and open wounds
(d) All

12. Breakfast in the morning before going to wards lessens the risk of getting any disease:
(a) Agree
(b) Do not agree

13. Apron is considered as personal protective equipment?
(a) True
(b) False

14. Which viral markers should be done in case of splash of fluids or needle stick injury?
(a) HIV only
(b) HIV, HBsAg, HCV
(c) HIV, HBsAg, HCV, RPR
(d) $\mathrm{C}$ reactive protein

15. Have you taken Hepatitis B vaccination?
(a) Yes
(b) No

16. Which is vaccine preventable disease?
(a) HIV
(b) HbsAg
(c) $\mathrm{HCV}$
(d) None

17. What is the schedule of Hepatitis B vaccination?
(a) $0,1,6$
(b) $0,1,3$
(c) $0,1,2$
(d) $0,1,12$

18. If needle stick injury with HIV positive blood is done, what is the ideal time you should start post exposure prophylaxis?
(a) Within 4 hours
(b) Within 1 hour
(c) Within 24 hours
(d) Within 72 hours 
19. Mode of transmission of Leptospirosis is?
(a) Respiratory route
(b) Touching a diseased person
(c) Contact of leptospirae contaminated water on open wound area
(d) None

20. How Hepatitis b is transmitted?
(a) Blood transfusion
(b) Sexual route
(c) Perinatal route
(d) Touching
(e) A, b, c
(f) All

21. What is the most important primary precaution for infection control in hospitals which is often neglected by us?

(a) Vaccination against transmissible disease

(b) Proper hand washing

(c) Medical mask

(d) Apron

\section{Result}

Total 143 2nd year MBBS students responded to the questions. Figure 1 shows responses of students.

\section{Discussion}

A hospital infection control policy with an integrated and monitored program is the key component in HAI prevention ${ }^{[1]}$. The health care workers including doctors, nurses and most importantly the medical students- both undergraduates and postgraduates also play the important role in HAI prevention if they are thought enough ${ }^{[5]}$.

The present study shows 40-60\% knowledge about needle stick injuries with only $30 \%$ showing correct response about needle recapping which is very less. It shows similar results with Ayub et $a l^{[5]}$, Kotwal et al ${ }^{[9]}$ and Kermode et al ${ }^{[10]}$. This suggests highly lacking knowledge about needle disposal as recapping increases chances of getting injuries and counter pricks with patients infected blood by many folds. Knowledge about transmission of tuberculosis was satisfactory (94\%) which shows similar results with Tenna et $a l^{[11]}$ but about MDR and XDR TB was up to 70-80 \% which is again a serious issue as nowadays prevalence of MDR and XDR TB is increasing rapidly. So students must

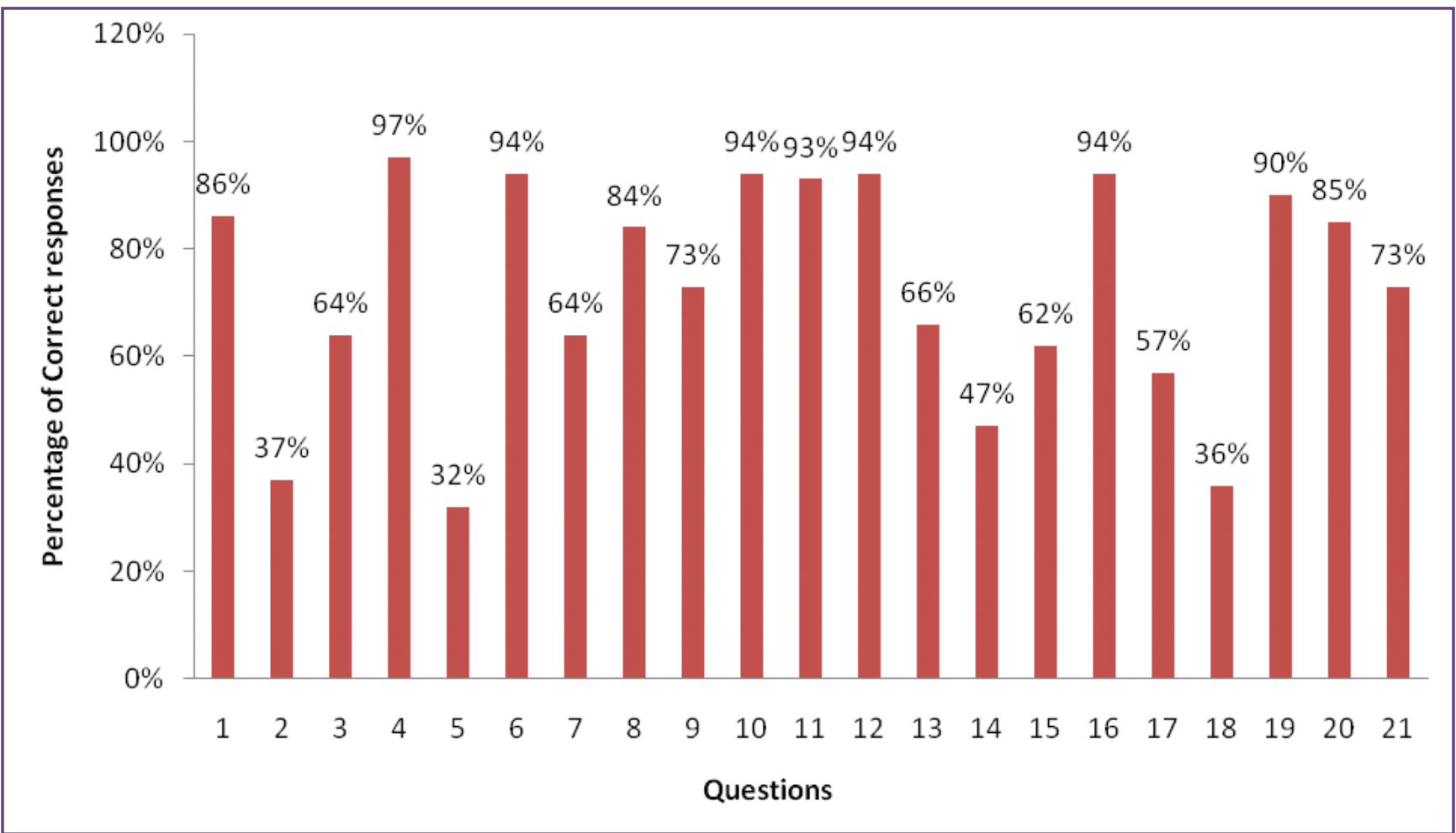

Fig. 1: Responses of 2nd year MBBS students to questions. 
be aware of this burning issue of the country. Knowledge regarding Swine flu transmission was up to $70 \%$ only. As Swine flu epidemics and pandemics are noted in different geographic areas of the world as well as in our region, it is mandatory for them to understand route of transmission of the disease to prevent more spread in case of epidemics.

Knowledge regarding personal protective equipments and precautions taken before going to wards shows good results with $80-90 \%$ which shows similarity with Yakob et al ${ }^{[12]}$. Response regarding consideration of apron as PPE was less that is up to $66 \%$. This needs to be taken into account as apron is the main stay of protection for doctors, nurses and students in wards or OPDs.

Assessment of knowledge regarding Hepatitis B virus was not up to the mark. Students knew it is a vaccine preventable disease and how it is transmitted but only around $60 \%$ knew the correct dosage schedule and the same have taken vaccination against the disease. This shows similar results with Singh et al ${ }^{[13]}$ and Saad Al Zahrani et al ${ }^{[4]}$. As Hepatitis B is the vaccine preventable disease, the compulsion should be made for vaccination of Hepatitis B to decrease risk of transmission.

Regarding post exposure prophylaxis, only 30-40 \% knew that it is to be started as early as possible, as every hour is important ${ }^{[14]}$. The more delay, the less effective is the treatment. The students must have appropriate knowledge about this as it is an emergency condition. $70 \%$ emphasized the importance of hand hygiene in HAI which is again a matter of concern, because proper hand washing is the one important primary step in prevention of infections as studies have shown multi drug resistant bacteria in the hands of health care workers which act as carriers ${ }^{[15]}$. This is in contrast to Tenna et al ${ }^{[11]}$ which shows $90 \%$ response. This is implemented to all those who are related with health care work starting from doctors, nurses, students to servants.

\section{Conclusion}

The study shows lack of knowledge and awareness amongst medical students about hospital acquired infections. There is need to educate them enough by means of various training with pre and post training evaluation, seminars, lectures, inter active classes and more curriculum activities regarding hospital acquired infection control. Hepatitis $B$ vaccination to all medical students on their admission or before going to clinics is highly recommended. More such studies should be done in future to assess knowledge, attitude and practice (KAP) score of the students and guide them well.
Limitations: We did not take training of the students, so pre and post training analysis could not be done. Questionnaire was based on knowledge only, so we could not assess attitude and practice of the students.

\section{Reference}

1. Disease C. Prevention of hospital-acquired infections World Health Organization. 2002.

2. Kotasthane DS, Kotasthane VD, K S, A A. Impact of intervention on awareness of biomedical waste disposal among medical students. Ann Pathol Lab Med. 2017;4(2):A195-202.

3. Sheth AM, Jani DS, Rangoonwala MM, Kadri AM. Assessing the awareness and practice of Hospital Acquired Infections ( HAIs ) among nursing staff of Civil Hospital, Rajkot, Gujarat, India. 2015;3(8):1844-50.

4. AlZahrani S, AlAmry F, Ghonaim M, AboSalem O. Awareness \&amp; knowledge of medical students \&amp; interns about infection control measures. Int J Med Sci Public Heal. 2013;2(3):331.

5. Cdt M, Ayub A, Goyal A, Kotwal A, Kulkarni A, Kotwal CA, et al. Infection control practices in health care : Teaching and learning requirements of medical undergraduates. 2012;9:10-5.

6. Hospital Infection Control Guidelines: India Council of Medical Research. Available from: http://icmr.nic.in/ guidelines/Hospital Infection control guidelines-2.pdf

7. Venkatesh S, Gupta, Sunil Jain S, Srikantiah, Padmini Gaind R. Hospital Infection Prevention and Control Guidelines. 2011;1-65. Available from: http://www.ncdc.gov.in/ writereaddata/mainlinkfile/File571.pdf

8. World Health Organization. Practical Guidelines for Infection Control in Health Care Facilities. World Heal Organ. 2004;110. Available from: http://www.wpro.who.int/ publications/docs/practical_guidelines_infection_control. pdf

9. Kotwal A, Taneja DK. Health care workers and universal precautions: perceptions and determinants of noncompliance. Indian J Community Med. 2010;35:551e553.

10. Kermode M, Jolley D, Langkham M, Thomas MS, Crofts N Occupational exposure to blood and risk of bloodborne virus infection among health care workers in rural north Indian health care settings. Am J Infect Control. 2005;33:34e41.

11. Tenna A, Stenehjem EA, Margoles L, Kacha E, Blumberg HM, Kempker RR. Infection control knowledge, attitudes and practices among healthcare workers in Addis Ababa, Ethiopia. Infect Control Hosp Epidemiol. 2013;34(12):1289-96.

12. E Y, T L. Knowledge, Attitude and Practice towards Infection Control Measures among Mizan-Aman General Hospital Workers, South West Ethiopia. J Community Med Health Educ.2015;5(5). 
13. Singh A, Jain S. Prevention of Hepatitis B-Knowledge and Practices Among Medical Students. 2012; (February):52-6.

14. Services H. Updated Guidelines for Antiretroviral Postexposure Prophylaxis After Sexual, Injection Drug
Use, or Other Nonoccupational Exposure to HIV — United States, 2016.

15. Infections I. Evidence of hand hygiene to reduce transmission and infections by multi- drug resistant organisms in healthcare settings. (1):1-7.

*Corresponding author:

Dr. Latika Nitin Purohit, 51, Aagam Heritage, Opp. Someswar Arcade, Vesu, Surat, Gujarat - 395007, India

Phone: +919428509649

Email: drlatikanitin@gmail.com

Financial or other Competing Interests: None. 